\title{
Migración circular en tiempos de crisis. Mujeres de Europa del Este y africanas en la agricultura de Huelva ${ }^{1}$
}

\author{
Estrella Gualda
}

Universidad de Huelva. Estudios Sociales e Intervención Social (ESEIS)

estrella@uhu.es

Recibido: 18-10-2011

Aceptado: 16-03-2012

\section{Resumen}

En este artículo, enmarcado en las nuevas políticas europeas respecto a la migración circular y a la contratación en origen, se estudian los procesos de sustitución laboral y étnica que han tenido lugar en Huelva (España) con motivo de la temporada de la fresa. Se emplea una metodología plural para el análisis de datos que se beneficia de diversas encuestas, grupos de discusión, entrevistas a expertos y análisis de la prensa local y otros documentos secundarios generados desde 1999. Se descubre que, frente a otros escenarios agrícolas del territorio español, la última década se ha caracterizado por una progresiva sustitución y feminización de la mano de otra agrícola. Así, si el proceso de sustitución laboral reemplazó españoles por marroquíes varones, de ahí se pasó a contratar a mujeres del este y posteriormente africanas, estas últimas contratadas en el contexto del proyecto europeo Aeneas. Se discute sobre las luces y las sombras de la migración circular y de las contrataciones en origen y se observa que la agudización de la crisis internacional, que provoca una vuelta al campo de muchos españoles, abre nuevas incógnitas sobre el desarrollo futuro de las políticas de migración circular en el área, presentándose resultados que pueden ser de interés para otras áreas donde se estén desarrollando este tipo de políticas para la regulación de los flujos migratorios.

Palabras clave: inmigración; mujer; europeas del este; africanas; marroquíes; contratos en origen; crisis económica; agricultura; migración circular; Huelva (España).

1. Se presentó una versión preliminar de este artículo en la mesa de género y migraciones en el VI Congreso sobre las Migraciones en España, que tuvo lugar en La Coruña entre el 17 y el 19 de septiembre de 2009. Se ha beneficiado también de mi estancia en la Universidad de Princeton en 2011, gracias a la financiación del Ministerio de Educación, Programa Nacional de Movilidad de Recursos Humanos del Plan Nacional de I-D+i 2008-2011, Programa Salvador de Madariaga (PR2010-0524) y a la hospitalidad del Center for Migration and Development, dirigido por Alejandro Portes. Agradecemos igualmente los comentarios y las sugerencias recibidos en el texto final por varios evaluadores anónimos. 
Abstract. Circular migration in a time of crisis: Eastern European and African women in the agricultural sector of Huelva (Spain)

This article, which is framed within the new European policies on circular migration and the quota systems established in Spain for the recruitment of workers in sending countries, examines the processes of labour and ethnic substitution of workers that take place in the province of Huelva (Spain) during the strawberry harvest season. We use a plural methodology to analyse data collected from several surveys, focus groups, interviews with experts, local press and statistical data from a period beginning in 1999. We find that, compared to other agricultural scenarios in Spain, the last decade was characterised by a progressive substitution and feminisation of agricultural labour. In sum, while Moroccan men replaced Spanish workers in a first instance, this process was followed by Polish, Romanian, Bulgarian and later African women who substituted Moroccan men in the strawberry fields, thus starting the feminisation process. Following the new enlargement of the European Union, a new Aeneas Programme for recruiting workers was implemented with the support of new European policies to promote circular migration, and farmers began hiring Moroccan women. A pilot programme was also developed to hire Senegalese women. In this article we explain the process in the context of the international economic crisis, and examine the lights and shadows that play a role in the story. The return of Spanish labourers to agriculture in a time of crisis time poses new questions for the future of migratory policies in this area, especially when regulated through circular migration. Our results can be useful for other fields as well as for policymakers due to their policy implications.

Keywords: immigration; gender; Eastern European women; African women; Moroccan women; contracts in origin; economic crisis; agriculture; circular migration; Huelva; Spain.

\section{Sumario}

1. Nuevas experiencias y reconceptualizaciones de la migración circular

2. Migraciones circulares en Europa y contratación en origen

3. En un contexto de desempleo

4. Metodología y objetivos e ideas de partida
5. El cambio en las pautas de contratación en cuanto al perfil sociológico de género y país de origen

6. Los efectos de la crisis y el regreso de españoles al campo: discusión

7. «Manteniendo la máquina engrasada». Esbozo de conclusión

Referencias bibliográficas

\section{Nuevas experiencias y reconceptualizaciones de la migración circular}

Aunque, en ocasiones, el término migración circular ha estado asociado a las migraciones laborales y de temporada, y bastantes veces se ha referido a las migraciones agrícolas (por su componente estacional), la bibliografía internacional permite constatar la diversidad de experiencias migratorias que se describen aludiendo al mismo. Así, por ejemplo, algunas de las líneas de trabajo más interesantes en los debates recientes conectan cuestiones como la integración, el transnacionalismo y la migración circular, sugiriendo que los protagonis- 
tas de la migración circular suelen estar más arraigados al origen que los que cuentan con un perfil transnacional, con una integración más híbrida. Parrenas se refiere, por ejemplo, a los artistas filipinos que se desplazan a Japón, cuyos retornos continuos al lugar de origen son descritos como un factor limitador de la integración en el lugar de destino (Parrenas, 2010). Otras aproximaciones asocian la migración circular con la construcción de identidades, argumentando que las idas y venidas de los inmigrantes contribuyen a hacer borrosos los límites comunitarios o desdibujan y relativizan las identidades (McKay, 2006).

La circularidad en las migraciones ha sido descrita en este siglo como un instrumento que puede aliviar la pobreza en los lugares de origen, con lo cual contribuye significativamente al desarrollo y a la mejora de las condiciones de vida en los países emisores de inmigrantes (Onyeonoru, 2006; De Haas, 2005). Y, en este sentido, se llegan a concebir como erróneas las políticas restrictivas que interrumpen la migración circular, puesto que con ello cercenan el desarrollo potencial de los países de origen (De Haas, 2005). Igualmente, políticas restrictivas desarrolladas ante el miedo de que la migración circular se convierta en permanente no consiguen frenar la llegada de inmigrantes, como suelen pretender, pero en cambio aceleran, a veces, como consecuencia no prevista, los procesos de reagrupamiento familiar y de asentamiento en el destino migratorio (véase, sobre el caso, México y Estados Unidos, en Massey, Durand y Malone, 2002), con lo cual se repite una historia que ya se ha vivido previamente en otros lugares, como fue el caso de Europa durante la crisis del petróleo de 1973 (Castles, 1985 y 1986; O’Brien, 1988), cuando se establecieron políticas como la alemana, que marcaba una fecha tope (Stichtag) para la concesión de permisos de trabajo a cónyuges e hijos de inmigrantes en los años siguientes a la crisis (Gualda, 2001). Este tipo de políticas, más que detener el crecimiento de la inmigración, indujeron a una rápida reagrupación familiar.

La prioridad dada a políticas restrictivas sigue teniendo lugar, así como los esfuerzos para regular, en este nuevo mundo global, los tránsitos circulares entre diferentes países, aunque si detenemos nuestra mirada en Europa, donde se sitúa este artículo, el acento parece haberse desplazado, como veremos un poco más adelante, hacia la intención de intentar establecer vínculos entre migración circular y codesarrollo.

Precisamente, una de las principales aportaciones de este trabajo es que presenta, desde un abordaje longitudinal, cómo ha venido siendo el proceso de contratación de mano de obra para la temporada agrícola de Huelva y cómo esta contratación se ha visto afectada por el tránsito hacia nuevas políticas europeas respecto a la gestión de la migración circular y el retorno. La experimentación de un proyecto piloto de migración circular apoyado por la Unión Europea para la gestión de los flujos migratorios (Aeneas) es descrita y evaluada a través de estas páginas prestando especial atención a cómo va cambiando la participación laboral femenina al hilo de los cambios en las políticas migratorias y el escenario internacional. El entrecruce entre género, agricultura, políticas de migración circular y codesarrollo da especial valor a este trabajo, que quiere contribuir, exponiendo este caso, al debate interna- 
cional y a las reflexiones sobre las nuevas prácticas de migración circular, sus ajustes en momentos de crisis y su reconceptualización en contextos donde la idea de codesarrollo adquiere protagonismo.

\section{Migraciones circulares en Europa y contratación en origen}

No parece fácil definir de forma absolutamente precisa el término migración circular. De hecho, a veces se usa de forma intercambiable a otros conceptos como el de migración temporal. La dificultad de definición se acrecienta cuando este tipo de conceptos son descritos como categorías conceptuales o analíticas, sin coincidir exactamente con lo que miden las estadísticas o lo que establecen las leyes o las políticas al respecto (Wiese y Thorpe, 2011; Newland, 2009).

Algunas ideas que comúnmente suelen considerarse en la bibliografía para aludir a la migración circular tienen que ver con las dimensiones espacial, temporal, iterativa y de desarrollo, recientemente señaladas por Newland (2009). Migración circular se concibe, así, como una migración no permanente, que implica la emigración de un país a otro por diferentes razones (laborales, académicas, de supervivencia, etc.). No puede entenderse el término sin la idea de retorno, así como de la posible repetición del movimiento migratorio (ciertas idas y vueltas, o movimiento cíclico o periódico, a veces estacional). Una segunda idea tiene que ver con la duración de la migración, la cual hipotéticamente no sería muy larga, de tal forma que normalmente no se consideraría como migración circular aquélla que supone un retorno tras una larga estancia de asentamiento en un país (por ejemplo, el retorno jubilación). No es infrecuente delimitar periodos concretos para migraciones de temporada (por ejemplo, para la agricultura), que se vinculan al retorno y a la posibilidad de tener algunos derechos reconocidos para poder regresar en años sucesivos (Ministerio de Trabajo e Inmigración, 2010b, o, en otros ámbitos, Wiese y Thorpe, 2011). En cualquier caso, siempre puede ocurrir que lo que se inició como un movimiento de migración circular acabe desembocando, a la larga, en un asentamiento permanente, aspecto que ha solido preocupar en algunos ámbitos y ha sido la base de algunas políticas restrictivas.

La migración circular, como una de las formas en que se desarrollan las migraciones internacionales, tiene una larga historia, especialmente si pensamos en movimientos espontáneos caracterizados por ciclos repetitivos de emigración y retorno, como vía natural de adaptación. Estos movimientos se han venido produciendo muchas veces entre países vecinos, aunque su registro estadístico haya sido insuficiente o no haya tenido lugar, como ya señala Hugo (1982) respecto a Indonesia. Este tipo de movimientos cíclicos de población, pero de forma más planificada, se han encontrado en diversos momentos de la historia contemporánea. Recuérdense, por ejemplo, el programa Bracero, que regulaba la migración entre Estados Unidos y México (1942-1964) (Massey, 1987; Cerrutti y Massey, 2004), o los programas para contratar Guestworkers o Gastarbeiter, que tuvieron lugar en varios países de la Europa Central (Castles, 2006; Gualda, 2001; Böhning, 1974; Kayser, 1977; 
Kuhn, 1978), así como otras experiencias de contratación temporal (Portes, Guarnizo y Landolt, 1999).

Newland (2009) argumenta que uno de los aspectos distintivos hoy del uso del término migración circular es precisamente que está en las agendas de los gobiernos, con lo cual se desarrolla como una herramienta política para regular algunos flujos migratorios del siglo XXI. Otro de los elementos que marcan la diferencia con el pasado es que los actuales programas de migración circular parecen prestar más atención al desarrollo de los países de origen. Castles (2006) coincide también en este particular cuando se pregunta sobre si la migración circular puede ser vista como una especie de «resurrección» de los programas precedentes de «trabajadores invitados». Argumenta que mientras que los programas de antaño se diseñaron de forma unilateral para beneficiar a los países demandantes de trabajadores, los que se empiezan a esbozar en la Unión Europea parecen buscar el desarrollo de los países de origen. Pero, según opina, aún necesitan que se produzca un cambio en la voluntad política y la implicación de multiplicidad de agentes sociales para su ejecución.

Este nuevo eje puesto en el desarrollo de los países de origen hace que no resulte extraño, entonces, que la migración circular haya sido evaluada recientemente como un instrumento político que puede tener repercusiones positivas para el desarrollo humano, en la medida en que los inmigrantes pueden beneficiarse de la circularidad (Newland, 2009; International Organization for Migration, 2010). Pero la reintroducción de programas de migración temporal no está exenta de controversias, si bien algunos analistas como Ruhs (2006) argumentan que, bajo determinadas condiciones, estos programas pueden generar beneficios netos significativos, tanto para los países receptores como para los países emisores y para los mismos inmigrantes. La implicación política en estos programas, así como cierta intervención en el mercado de trabajo, son dos factores necesarios a su modo de ver. Los nuevos programas, por otra parte, se sitúan en escenarios diferentes a los de antaño, si pensamos en términos de globalización y de facilidades para la movilidad y las comunicaciones (Hugo, 2006; Sassen, 1988).

Recientemente, la Unión Europea ha venido trabajando en una serie de planes y directivas que, contextualizadas en el intento de conseguir una política común para promover la inmigración legal de nacionales de terceros países, ha introducido la migración circular como uno de los instrumentos para el desarrollo de la inmigración laboral y la compensación de los efectos negativos del envejecimiento demográfico y el ajuste a las necesidades del mercado de trabajo (European Commission, 2011). La apuesta por un desarrollo progresivo de las migraciones circulares debe entenderse en el contexto de los esfuerzos de la Unión Europea por combatir la entrada ilegal de inmigrantes, el refuerzo de las fronteras y de la seguridad, la lucha contra el contrabando y el tráfico de personas (Commission of the European Communities, 2004, 2005a y 2005b), así como, entre otros, de los esfuerzos para promover el retorno y la reintegración laboral de los inmigrantes y la readmisión de inmigrantes irregulares. En todo este contexto, y empezando por la negociación de algunos programas piloto 
para la experimentación y la evaluación de la viabilidad del concepto nuevo de migración circular (Commission of the European Communities, 2007; Council of the European Union, 2007), se dispone el programa Aeneas (European Parliament and Council of the European Union, 2004), donde se encuadra una parte de la reciente experiencia onubense. Según indica el artículo 1: «La Comunidad establece por la presente un programa de cooperación [...] cuyo objetivo será prestar ayuda financiera y técnica específica y complementaria a terceros países para apoyar su labor destinada a gestionar mejor los flujos migratorios en todas sus dimensiones».

Junto a este objetivo, se articulan otro conjunto de ellos que son acordes al marco legislativo europeo que ha venido desarrollándose posteriormente y que recogimos arriba. En lo que más nos concierne en este artículo, a partir del lanzamiento del programa Aeneas, se da lugar al proyecto Aeneas Cartaya ${ }^{2}$, desarrollado en la provincia de Huelva, que se concibe como un programa integral para la gestión de la inmigración estacional. Este programa se comienza a aplicar cuando ya existía una rodada experiencia en esta provincia española respecto a las contrataciones en países de origen, como más adelante describimos. La gestión colectiva de las contrataciones en origen y el régimen de los trabajadores de temporada quedaban regulados en los artículos 39 y 42 ya en la Ley 4/2000 (Ministerio de Trabajo e Inmigración, 2010b). Respecto a las contrataciones en origen, las ofertas de empleo, una vez examinada la situación laboral nacional, debían orientarse preferentemente hacia los países con los que España hubiera firmado acuerdos sobre la regulación de flujos migratorios, cosa que no cambia con la Ley Orgánica 2/2009, de 11 de diciembre, y el nuevo reglamento recientemente aprobado que la desarrolla.

Hay que subrayar también la orientación que se da hacia África respecto a la gestión colectiva de las contrataciones en origen, palpable en el nuevo Reglamento (título VIII). Recientemente, el Ministerio de Trabajo e Inmigración (2010b), a través de la Orden TIN/3364/2010, de 28 de diciembre, por la que se regulaba la gestión colectiva de contrataciones en origen para 2011, claramente indicaba que «2. Las ofertas se orientarán preferentemente a los países con los que España tiene suscritos acuerdos sobre regulación y ordenación de flujos migratorios: Colombia, Ecuador, Marruecos, Mauritania y República Dominicana; o, subsidiariamente, instrumentos de colaboración en esta materia: Gambia, Guinea, Guinea Bissau, Cabo Verde, Senegal, Mali, Níger, México, el Salvador, Filipinas, Honduras, Paraguay y Argentina; o con los que los suscriba, en su caso, en el periodo de vigencia de esta Orden». Los países de referencia han variado tras la incorporación de algunas naciones como Polonia o Rumanía a la Unión Europea.

Estos nuevos horizontes de política migratoria y acuerdos internacionales, situándonos ahora en el artículo, tanto en el plano europeo como en el nacional, marcarán una serie de cambios decisivos respecto a los derroteros que tomará la campaña de la recogida de la fresa en Huelva, pues los agricultores

2. Ref. MIGR/2005/103-564-48. 
han tendido a solicitar trabajadores teniendo en cuenta estas recomendaciones, como seguidamente expondremos. Con el tiempo, se irá observando una progresiva sustitución étnica en la mano de obra que trabaja en la agricultura.

\section{En un contexto de desempleo}

La cosa es que ahora, con la crisis, a mucha gente de aquí no le importaría trabajar en el campo, pero claro, muchos empresarios no quieren contratar a gente del pueblo porque en una época los dejaron colgados; por eso, aunque se intenta que contraten a gente de aquí y se habla con ellos, también parece normal que no se fíen y prefieran traer a gente de fuera que les están respondiendo bien. (GD7, mujer de Lepe, abril de 2009).

El fragmento anterior, extraído de un grupo de discusión (GD) que fue celebrado con población nacional en un municipio agrícola onubense, representa una parte del discurso local que gira en torno a la campaña agrícola, la contratación en origen y la crisis. La cita correspondía a un momento donde la crisis se estaba empezando a notar en el crecimiento del desempleo, pero aún éste no era tan agudo como ahora. El discurso de esta mujer condensa algunas pautas básicas de la evolución que se ha producido en Huelva respecto a la sustitución de la mano de obra local por mano de obra extranjera, especialmente intensa desde los años noventa. Se anotan también algunas pinceladas de las reacciones de la población ante el hecho de que se contrate a población extranjera cuando crece el desempleo en Andalucía y en la provincia de Huelva.

El desempleo andaluz es un fenómeno estructural, y es habitual encontrar que las tasas de paro de la región se encuentren por encima de las tasas de paro españolas. El gráfico 1, confeccionado a partir de los datos que se publican en la Encuesta de población activa, revela esta pauta durante todo el período que va desde inicios de 1976 hasta finales de 2010. Aunque la evolución es similar, las tasas de desempleo andaluzas (incluyendo la de Huelva) son superiores a la media nacional (gráficos 1 y 2).

Lo que más diferencia globalmente las tasas de paro de Huelva de las de Andalucía y España es su componente estacional. Se constata que, sistemáticamente, durante los trimestres segundo y tercero del año, se ha venido produciendo una reducción cíclica de las mismas. Esta reducción se explica, en gran medida, por el incremento de la contratación en la agricultura y en los servicios. Esta pauta estacional se aprecia con más nitidez en el gráfico 2, que recoge datos desde 2005 hasta 2010, y que permite entender mejor los picos que se apreciaban en el gráfico 1. Estamos hablando de los meses álgidos de la campaña agrícola onubense especialmente y del empuje turístico, que se suceden temporalmente y hacen caer estacionalmente la tasa de paro. La tendencia al incremento del desempleo durante la crisis en los últimos años, con la salvedad de las oscilaciones estacionales, es evidente en la provincia de Huelva. Así, si en el cuarto trimestre de 2005, la tasa de paro era del 16,9\%, cinco años más tarde, en 2010, alcanzaba el 30,6\%. 


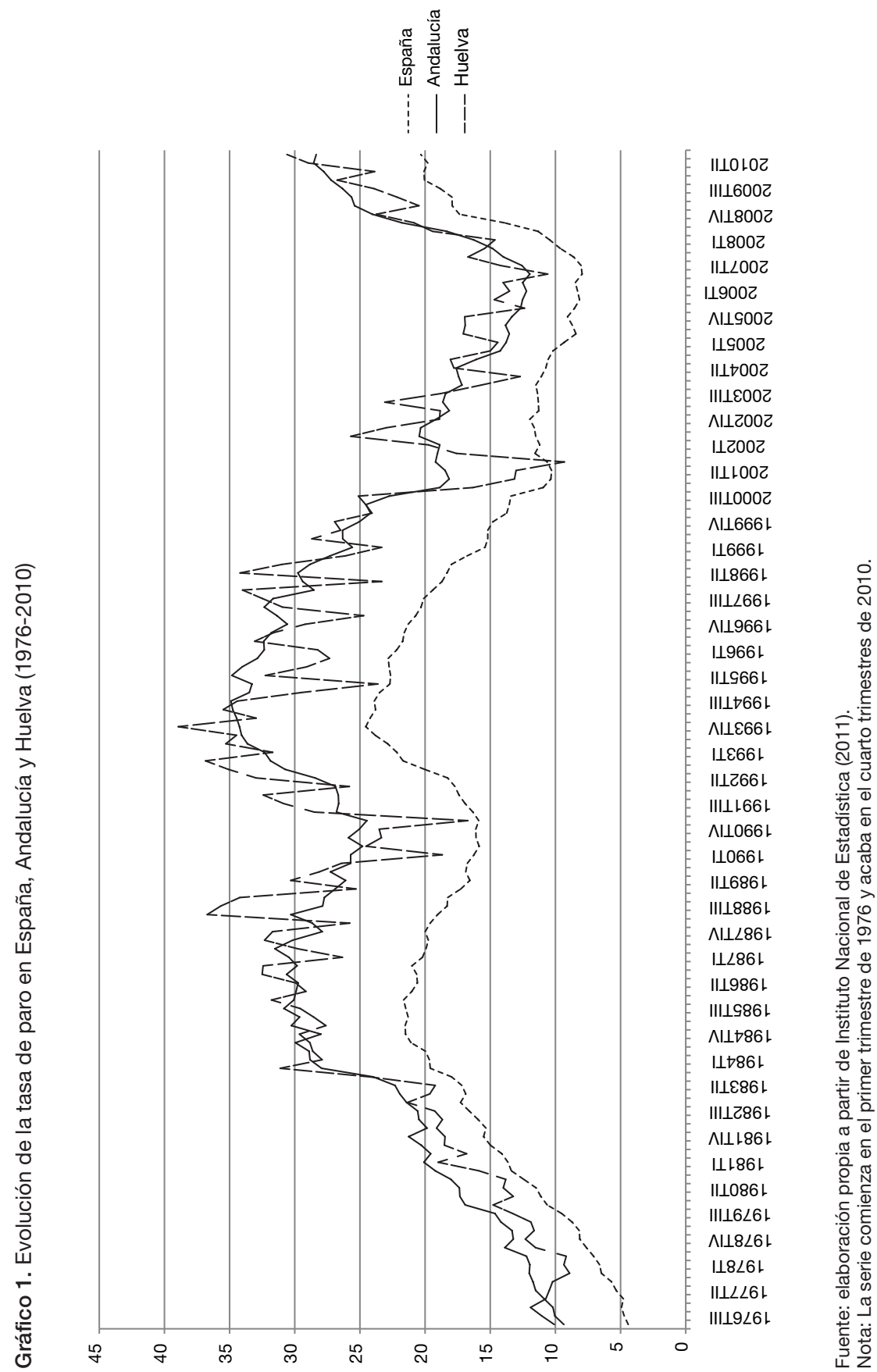


Gráfico 2. Evolución de la tasa de paro en España, Andalucía y Huelva (2005-2010)

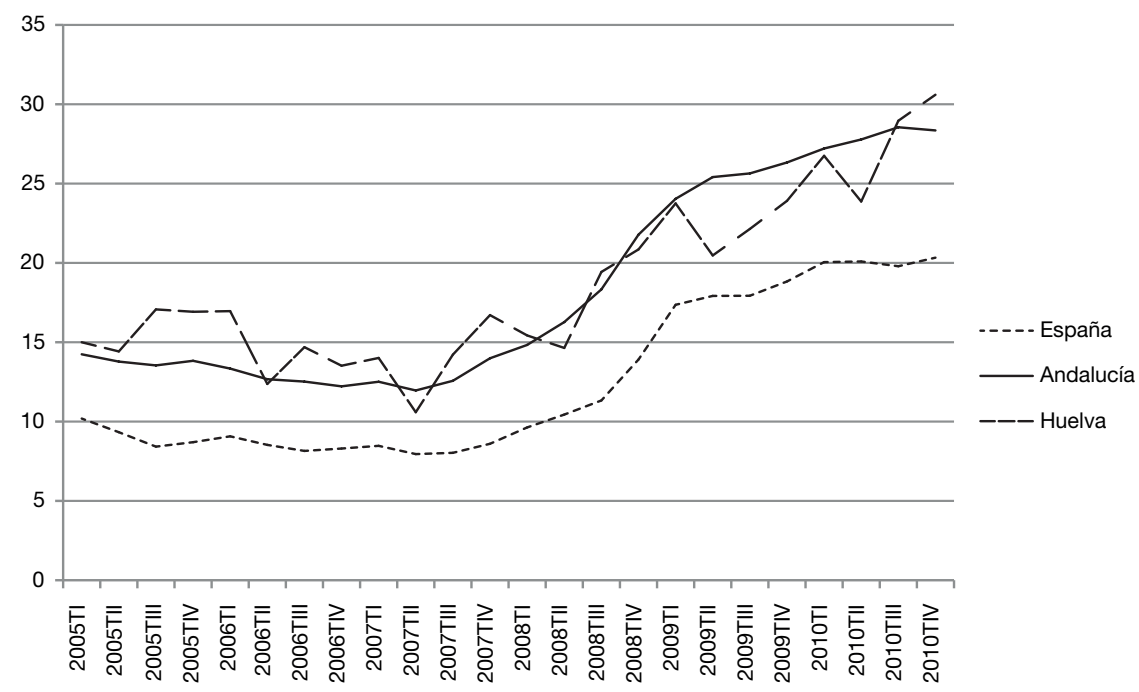

Fuente: elaboración propia a partir de Instituto Nacional de Estadística (2011).

Nota: La serie comienza en el primer trimestre de 1976 y acaba en el cuarto de 2010.

En las páginas que siguen, realizamos una descripción sobre cómo han ido cambiando las pautas de contratación en la agricultura onubense (especialmente con relación al género), expondiendo qué otros elementos del contexto han participado en el proceso. Tras conocer cómo se ha ido desarrollando la contratación en origen en los últimos años, en el marco de las recientes políticas europeas de migración circular, nos detenemos al final en algunos aspectos que la crisis económica parece estar removiendo desde el punto de vista local. Aunque en primer lugar perfilamos brevemente los detalles metodológicos de este trabajo, así como nuestros objetivos y nuestras ideas de partida.

\section{Metodología y objetivos e ideas de partida}

Este trabajo se fundamenta empíricamente en diversas investigaciones que, desde el año 1999, venimos realizando en la provincia de Huelva ${ }^{3}$. Para ello, hemos empleado técnicas diversas, a resaltar:

3. Dada la cantidad y la variedad de información recopilada hasta el momento sobre esta cuestión a través de los proyectos ejecutados por el grupo de investigación Estudios Sociales e Intervención Social y por razones de espacio, eludimos citar en este apartado, una a una, las fichas técnicas de estas investigaciones. Pueden consultarse estos detalles concretos, así como publicaciones derivadas de las mismas, en http://eseis.es. 
a) Empleo de fuentes secundarias (estadísticas, memorias de entidades y anuarios).

b) Seguimiento y análisis de la prensa local relativa a la inmigración desde 1999 hasta hoy (Huelva Información, Odiel Información y, más recientemente, El Mundo — versión local-).

c) Dos encuestas a muestras representativas sobre las actitudes ante la inmigración (una dirigida a la población general y otra, a escolares).

d) Varias decenas de entrevistas a agentes sociales de la inmigración en Huelva (trabajadores sociales, directivos de asociaciones, etc.).

e) Multiplicidad de entrevistas e historias de vida a inmigrantes.

f) Una veintena de grupos de discusión en Huelva y provincia (mixtos, de hombres, de mujeres; de población española, de población inmigrante —adultos y jóvenes inmigrantes, según el caso-).

g) Observación y visita de espacios laborales de la inmigración, así como de lugares de residencia y asentamiento.

Las reflexiones y los datos que se aportan en el artículo se enfocan, desde una óptica del cambio social, a intentar responder a dos objetivos. Primero, describir el proceso habido en lo que respecta a la sustitución étnica que se produce en el mercado de trabajo agrícola, al hilo de los cambios en las políticas internacionales y migratorias. Segundo, discutir sobre algunos de los efectos que la crisis económica internacional parece estar produciendo en los procesos de contratación agrícola de inmigrantes, así como las respuestas de la población autóctona al respecto. Es desde esta óptica que empleamos el material recopilado citado arriba. Para responder a ambos objetivos, prestamos especial atención a los elementos del contexto que han ido influenciando el devenir de la contratación en origen en los últimos años. ¿Puede la crisis suponer una ruptura en la gestión de la mano de obra agrícola para años venideros? Antes de llegar a ese punto, conviene describir el proceso de cambio. Una de nuestras ideas de partida principales, que exploramos a través de nuestro caso concreto, es el vínculo estrecho que se establece entre los entornos económicos y políticos supranacionales y los contextos regionales y locales, de forma tal que las decisiones y las situaciones que ocurren en los escenarios macrosociales se concretan y no pasan desapercibidas en escenarios mesosociales y microsociales. Además de este estrecho vínculo, que genera una gran dependencia en escenarios locales respecto de lo que ocurre a nivel global, restando márgenes de maniobra en situaciones concretas como la contratación de mano de obra, se parte de la idea de que este tipo de dinámicas relacionales y de dependencias macro, meso y micro en el contexto de la contratación de mano de obra extranjera, se ha consolidado con el tiempo, aunque la casuística específica de leyes, personas contratadas, etc. pueda ir variando.

\section{El cambio en las pautas de contratación en cuanto al perfil sociológico de género y país de origen}

Es patente la importancia en España del número de mujeres inmigrantes asalariadas que actualmente conforman la mano de obra femenina agraria (Minis- 
terio de Agricultura, Pesca y Alimentación, 2008). En el caso que nos ocupa, antes de que llegara a consolidarse el proceso de feminización de los asalariados en el campo onubense, se produjo el abandono de la mano de obra local en la recolección de la fresa por motivos que tuvieron que ver con un ascenso en las aspiraciones laborales y en los logros educativos de los autóctonos (Márquez, Gordo y Delgado, 2008; para España, véase en Cachón, 2002 y 2009). Es especialmente a partir de la década de 1990 cuando se empieza a producir el proceso de sustitución de mano de obra española por extranjera, y podría decirse que, ya en el siglo XXI, la agricultura se ha convertido en una puerta de entrada para mujeres extranjeras en Huelva, lo cual responde de alguna forma - aunque con sus peculiaridades - a procesos de feminización de las migraciones que se observan en otros escenarios (Oso y Garson, 2005). Ello puede ocasionar cambios relevantes en los lugares donde se intensifica el asentamiento femenino (Beguy, Bocquier y Zulu, 2010).

En los últimos años, la llegada de extranjeros a la agricultura ha estado protagonizada por un modelo de selección del nuevo personal basado en el "contrato en origen", incentivado por la existencia de acuerdos internacionales entre España y los principales países que aportan personal a la campaña. En este sentido, suscribimos con Gordo (2009) que la evolución de la contratación en origen de temporada en la provincia está ligada a aspectos que tienen que ver con «razones diplomáticas [...] motivos políticos y de posicionamiento estratégico» (p. 159-160). Pero, como ya hemos desarrollado en otro lugar (Gualda y Ruiz, 2004; Gualda, 2009a), estos aspectos macrolocales se combinan con decisiones en el ámbito empresarial y responden igualmente a cómo los empresarios van evaluando las experiencias locales de campañas agrícolas previas.

La selección de personal para la recolección, y su llegada Justo a tiempo $o^{4}$, es clave para que la campaña agrícola sea exitosa. Y ésta es una preocupación central. No puede perderse de vista la importancia cuantitativa de los inmigrantes que trabajan en la agricultura onubense, puesto que se trata de una de las provincias en España que viene contando con mayor número de contratos agrícolas. De hecho, en el año 2009, es, según el Anuario Estadístico de Inmigración del Ministerio de Trabajo e Inmigración (2010a), la que cuenta con mayor número de contratos registrados de trabajadores extranjeros en la ocupación de «peones de la agricultura y de la pesca». Se contabiliza la cifra de 57.486, seguida de Valencia (con 53.807 contratos) y de Almería (con 43.096). El tipo de producto que se recolecta es intensivo en cuanto a la necesidad de mano de obra. Como es sabido,

4. Justo a tiempo, o Just in time (JIT), es una expresión estrechamente vinculada a los procesos de producción y distribución de mercancías en los entornos empresariales. Se trata de una filosofía que se aplica en la gestión empresarial (unida a veces a una gestión de «calidad total») con la idea de que la cadena de producción y distribución sea continua y tenga el menor número de interrupciones posibles (por ejemplo, evitando tiempos muertos o de espera), además de permitir ahorrar espacios de almacenamiento. Algunas de las ideas básicas de esta filosofía, que se idea para optimizar los beneficios en los sistemas productivos, se identifican en algunos parámetros con los que se está gestionando la gestión del flujo de mano de obra en las contrataciones en origen. 
la provincia de Huelva se especializa en la fresa y el fresón (aunque también se cultivan otros productos). Es la principal productora en España de dichos productos agrícolas (Ministerio de Medio Ambiente y Medio Rural y Marino, 2009) $\mathrm{y}$ una de las principales a escala mundial (Food and Agricultural Organization of the United Nations, 2010). Esta agricultura intensiva, basada en el popularmente llamado «oro rojo» o la fresa, ha sido la base, sobre todo desde la década de 1990, de un intenso movimiento de población inmigrante.

Desde una óptica estructural, no dejan de causar estupor los intensísimos cambios que han operado en la provincia respecto a la sustitución de mano de obra, que ha removido, a modo de un "terremoto", la estructura social (Beltrán, 2002), la composición sociológica de la mano de obra agrícola dedicada a la campaña. La sustitución (nunca completa) ha seguido varias fases que se describen seguidamente. Se trata de un triple relevo: de nacionales por extranjeros varones (en un primer momento), de varones por mujeres del Este (en un segundo momento) y de mujeres del Este por mujeres africanas (en un tercer momento), todo ello en un escaso intervalo de entre dos y tres lustros y fijándonos en los principales efectivos de trabajadores.

En términos estructurales, hay, no obstante, un elemento que permanece constante y es la necesidad instrumental de los empresarios de proveerse de mano de obra para la recogida. La previsión de un agotamiento de la mano de obra aparece en diferentes momentos, sea por el abandono del campo por parte de los españoles, por las dificultades para conseguir la llegada de población polaca o rumana después de su entrada a la Unión Europea, por el aporte insuficiente de población de Bulgaria, etc. La perenne necesidad de disponer de trabajadores para un producto tremendamente perecedero como es la fresa da impulso a la contratación en origen, lo cual resuelve la búsqueda de mayor certidumbre, en la medida en que permite planificar la llegada de los trabajadores justo cuando es preciso 5 . Esta búsqueda de certidumbre es clave en el ámbito empresarial (Gordon, 1995; Mendoza y Hoggart, 2000).

\subsection{Sustitución de españoles por, principalmente, varones magrebies a finales del siglo $X X$}

Aunque la sustitución de mano de obra no ha sido nunca completa en el proceso que describimos, pues en todo momento han seguido trabajando autóctonos en el campo, hay un punto de inflexión en los noventa originado a raíz del progresivo abandono de la población española del campo, en un proceso motivado por la búsqueda de mejores posiciones ocupacionales, que fue propiciado, entre otros, por el auge de algunos sectores como el de la construcción y los servicios (restauración, turismo, etc.). El abandono del campo por parte de los españoles precipita progresivamente la sustitución de la mano de obra. Al tiempo que jornaleros españoles (sobre todo de Huelva, Cádiz, Sevilla, Córdoba y Extre-

5. Hasta el punto de que cuando, en algún año, se han producido inclemencias del tiempo tales como heladas, se ha retrasado la llegada de población a la provincia desde sus países de origen. 
madura) dejan de trabajar en la campaña, van entrando varones marroquíes, así como también algunos argelinos y algunas personas de otros países, con menor relevancia cuantitativa. A finales de los años noventa, la prensa local daba cuenta de estas necesidades de personal que tenían los empresarios para poder completar la temporada agrícola con éxito. En esta época, la mayor parte de los trabajadores inmigrantes de la campaña eran varones, mayoritariamente marroquíes. Como ya se ha descrito en otros lugares (Gordo, 2011; Gualda, 2008; Gualda, 2009a), diversas circunstancias sociopolíticas y culturales (política internacional, nueva política migratoria, encierros de inmigrantes, quejas de los empresarios por el abandono del campo ${ }^{6}$, etc.) van dando cabida a la posibilidad de contratar a mujeres, que, desde el principio, son concebidas como mano de obra más controlable. Esta mayor capacidad de poder controlar a las mujeres que a los hombres ${ }^{7}$ es un elemento recurrente en las entrevistas y grupos de discusión celebrados con empresarios y sus representantes, y explica en parte los avatares por los que ha ido desembocando la contratación. No obstante, como se irá exponiendo, no es el único motivo ${ }^{8}$, si bien es uno de los que pone el dedo en la llaga más claramente en cuestiones de género, puesto que se asocian perfiles estereotipados y, diríamos, cuasi «estandarizados» femeninos (menor conflictividad, mayor sumisión, etc.) a unas mejores capacidades y habilidades laborales (a éstas se suman otras como que las mujeres son más ordenadas, no ensucian tanto los campos, se pelean menos entre ellas en la convivencia cotidiana, etc.) (Marañón, Gualda y Valerdi, 2011; Gordo, 2011). No obstante, independientemente del género, diversas investigaciones ponen de manifiesto la importancia que para los empleadores tiene, no sólo en el marco de la agricultura, el control en el lugar del trabajo, por lo cual es valioso para ellos encontrar trabajadores flexibles y controlables (Shih, 2002), sean éstos varones o mujeres. Características como las propiciadas a través del contrato en origen, un contrato temporal y con posibilidad de repetir al año siguiente pero bajo una oferta nominativa si se retorna legalmente, hacen del mismo un instrumento útil para el empresario, porque simplifica unos procesos de contratación ya de por sí muy complicados, al tener que buscar la mano de obra en el extranjero. Podría

6. «Son personas que vienen aquí muy equivocaos [...] y cuando tú los contratas, porque eso me ha pasao a mí y llevan un mes cogiendo fresa se van y te dejan plantao, cogen y se van y no tienen consideración con ná, ése es el problema y la gente no los quiere», «Para mí lo principal es tener gente desde que empieza la campaña hasta que termina... Y tener gente desde que empieza la campaña hasta que termina te da mucha tranquilidad» (empresarios agrícolas, transcripción literal de un fragmento de un grupo de discusión de 2002 - Gualda, 2008-).

7. Que se experimenta, entre otras ocasiones, en el contexto de los encierros del año 2001 con motivo de las protestas por el endurecimiento de la Ley de extranjería.

8. Hay otros conectados que componen el cuadro y que continuamente se relatan como factores que hacen decantarse por mujeres en los últimos años: son menos conflictivas y trasnochan menos, lo que las hace mejores para un trabajo duro que comienza a primerísima hora de la mañana. Otro motivo sería que el empresario debe proveer de vivienda a la plantilla que viene del extranjero y, salvo en el caso de que se contrate a familias en la misma cuadrilla, se opta por tener en ellas sólo a mujeres, pues no se considera correcto que cohabiten personas de sexo diferente y que no pertenezcan a la misma familia en la misma casa. 
decirse lo mismo respecto a la no sindicación de las personas que trabajan bajo esta fórmula. A todo lo anterior, se suman las percepciones empresariales de que las mujeres, de forma genérica y después de un tiempo habiendo contratado varones para la recogida de la fresa, son una mano de obra más fácil de manejar y a la vez más productivas. En este sentido, independientemente de que esto sea o no real, hay que recordar con Abdullah (2005) la importancia que tiene el ideal del "otro dócil» y disciplinado, como ya ha sido puesto de manifiesto en otros mercados laborales en España (Solé y Parella, 2005).

\subsection{Mujeres de la Europa del Este en los albores del siglo XXI. ¿Un espejismo?}

La contratación en origen de mujeres del Este en la campaña agrícola se produce especialmente desde el año 2000, cuando viene el primer contingente importante de mujeres, principalmente de Polonia. Los «contratos en origen» de tipo temporal consisten básicamente en la organización de un dispositivo para la selección de mano de obra extranjera que se ha ido perfeccionando con el tiempo. Algunos de los defensores locales de esta política (proyecto Aeneas Cartaya, 2008; Millán, 2009) argumentan que este tipo de contratación es la solución a la demanda de mano de obra que hacen los empresarios locales, por varios motivos:

- Se trata de una mano de obra regularizada, que viene con los papeles en regla. Esto es, cuando el trabajador llega a España, cuenta ya con un contrato firmado tras una selección que tiene lugar en su país de origen unos meses antes.

- Tales contratos tienen una duración determinada, según la campaña y sus necesidades, y el trabajador está obligado a retornar a su país al término de la misma.

- Los trabajadores que cumplen estas condiciones pueden repetir en campañas posteriores sin pasar por el proceso de selección (de hecho, la selección distingue entre una oferta genérica y una nominativa para estos casos), acorde con la legislación española de la última década (Ministerio de Trabajo e Inmigración, 2010b).

- El empresario está obligado a pagar el viaje de venida del trabajador a España (y el trabajador pagará el viaje de vuelta a final de campaña).

- El empresario está obligado a facilitarle una vivienda que guarde unas condiciones mínimas que son inspeccionadas.

- Las condiciones laborales (salario, etc.) se regulan de igual forma que para los trabajadores agrícolas locales que hacen la recogida de la fresa y de otros productos, de acuerdo con los llamados "Convenios colectivos del campo".

Con amparo en el Reglamento de Extranjería (RD 2393/2004) en relación con los trabajos de temporada, progresivamente se fue incrementando el volumen de mujeres contratadas por esta vía. Así, si en una campaña se vienen a necesitar alrededor de 60.000 trabajadores $^{9}$, en 2007-2008 (punto más álgido)

9. En los últimos años, se han hecho estimaciones algo superiores, alrededor de 80.000, por un incremento en la superficie cultivada. 
Gráfico 3. Evolución del contrato de origen en Huelva

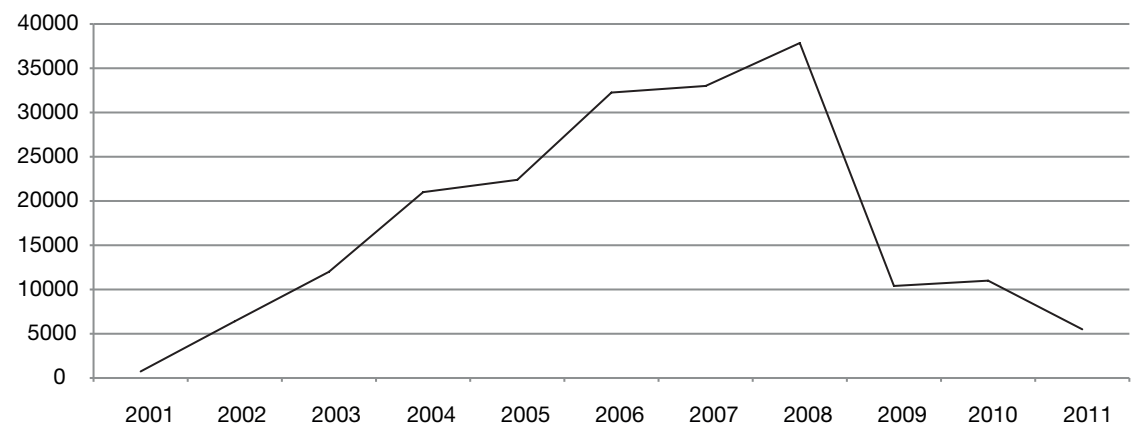

Fuente: Marañón, Gualda y Valerdi (2011).

se contrató en origen a más de la mitad (gráfico 3) ${ }^{10}$. En cambio, en las últimas campañas, caracterizadas por la crisis económica, se ha producido un retroceso y un punto de inflexión al respecto, con lo cual se ha reducido la contratación de extranjeros con el fin de promocionar el empleo local (de nacionales o de extranjeros residentes en la provincia). En el último de los casos, cuando se trata de personas de origen polaco, rumano, etc., al haberse incorporado a la Unión Europea, su entrada en el mercado de trabajo sería igual a la de los nacionales, de modo que la contratación en origen queda para otros.

La relevancia del impacto socioeconómico que supone esta contratación para la temporada sólo puede ser bien dimensionada si se tiene en cuenta que la población activa de toda la provincia para el último trimestre de 2010 era de algo más de 251.000 habitantes, en el cuarto trimestre había 174.000 ocupados y 25.500 ocupados desempleados, de acuerdo con los datos de la Encuesta de población activa del Instituto Nacional de Estadística. El impacto a nivel local es mayor del que sugieren estos datos, por cuanto no toda la provincia recibe población contratada en origen.

La evolución de los contratos en origen mostrada en el gráfico 3 permite ver claramente que en poco tiempo se produce un incremento exponencial de las contrataciones, que se acompañó de transformaciones importantes en cuanto al género y el país de origen. Y un volumen relevante de la población contratada se va sustituyendo atendiendo a las categorías de género, etnia o país de origen: varones marroquíes, mujeres polacas, rumanas, búlgaras, etc., con importancia variable según el año (gráfico 4). Desde que se da el paso de

10. La campaña implica una primera parte para la siembra, después del verano, y la parte más intensiva en mano de obra, desde febrero hasta junio, para la recogida (datos estimados a partir de la Subdelegación del Gobierno). Las cifras previstas inicialmente pueden variar a lo largo de la campaña, en función de si se consiguen las contrataciones finalmente. No existe una estadística oficial al respecto. 
sustituir hombres por mujeres, las preferencias de los empresarios agrícolas en cuanto a los trabajadores de campaña demandados se mantienen en femenino, aunque varían los países de procedencia. Conforme Polonia, Rumanía y otros se van incorporando a la Unión Europea, se producen nuevos cambios, entre otros factores, por el propio desinterés de esta población de seguir trabajando en el sector, pero también porque ya no procede la contratación en origen y se pueden realizar contratos más directos y nominativos como ciudadanos europeos. No obstante, a tenor de las estadísticas de contrataciones, aunque no sea por la fórmula del contrato en origen, sigue existiendo un grupo importante de mujeres del Este, incluida Polonia, trabajando en el campo ${ }^{11}$.

Independientemente del país de origen, hemos venido asistiendo a una especie de «terremoto demográfico» (Gualda, 2008) que presenta una cara femenina en los últimos años de la campaña, pues, literalmente, varios miles de mujeres han hecho presencia (cíclica) durante varios años en contados municipios onubenses y generan importantes impactos sociales y económicos: desde las contribuciones laborales positivas de las mujeres a la economía de la zona (en tanto que recolectoras), hasta la emergencia de nuevos negocios étnicos que ayudan a incentivar, pasando por el crecimiento de los emparejamientos de personas de origen diferente y, con el tiempo, la constitución de nuevas generaciones, así como por la eclosión de discursos estigmatizantes y muy negativos sobre la mujer inmigrante, derivados en gran medida del hecho que la intensa llegada de mano de obra para la agricultura es mayoritariamente femenina.

Pero la entrada en la Unión Europea de países proveedores de mano de obra agrícola, como Polonia, Rumania y Bulgaria ${ }^{12}$, convierte en espejismo lo que parecía había sido la salvación de la campaña agrícola, y se vuelve la mirada a África, de la mano ahora principalmente de mujeres marroquíes (Marañón, Gualda y Valerdi, 2011; Gordo, 2011; Moreno, 2009), y en el contexto del proyecto Aeneas Cartaya (2008), una de las experiencias piloto que financia la Unión Europea en un contexto de políticas que empiezan a definir y promover la migración circular.

\subsection{El retorno a Africa, ahora en femenino}

La orientación a Marruecos en las contrataciones en origen se debe básicamente a las dificultades para encontrar a polacas y rumanas, como se documenta perfectamente en la prensa local (véase nota a pie 13), a la incapacidad de Bulgaria para aportar tanto personal como era necesario (aunque algo contribuye), a

11. Las estadísticas publicadas, no obstante, adolecen a veces de la desagregación adecuada para afinar el análisis, pero el dato de contratos registrados en la agricultura por país de origen, unido al trabajo etnográfico entrevistando a empleadores y otros agentes locales, confirma esta circunstancia.

12. «La Comisión de Migraciones busca 8.000 extranjeros para la campaña. Estudia la posibilidad de traer mano de obra de Marruecos, Ucrania y Senegal», Odiel Información, 27 de diciembre de 2006: 18; «Asaja buscará temporeros en Ucrania ante las restricciones dentro de la UE», Huelva Información, 2 de diciembre de 2006: 20. 
la viabilidad de Marruecos ${ }^{13}$ y a las nuevas orientaciones políticas respecto a la migración circular. La nueva contratación de mujeres marroquíes, que se aprecia claramente en las estadísticas de contratos, coincide con la consolidación del proyecto Aeneas Cartaya y la reorientación de la contratación hacia África, y especialmente hacia Marruecos, en estos momentos iniciales (Moreno, 2009; Gordo, 2009). Marruecos es uno de los países que hace más tiempo tienen suscritos con España un acuerdo para la regulación y la ordenación de flujos migratorios, lo que facilita dicha gestión.

El proceso que se sigue repite la pauta que hubo con la población de Polonia y se experimenta primero en una campaña (2005-2006) en la que se contrata a un efectivo de trabajadoras más reducido. Esta experimentación, que permite evaluar todo el proceso e incluso ir puliendo detalles referentes a varios aspectos sobre cómo se coordinan todas las organizaciones implicadas en la logística de la contratación (incluidos gobiernos respecto a la cuestión de visados, preselección, etc.), se repetirá en 2007-2008 con la contratación de senegalesas. La cifra de mujeres marroquíes contratadas va creciendo tras el primer año experimental (Marañón, Gualda y Valerdi, 2011; Gordo, 2011), hasta que, con la crisis económica, se va reduciendo progresivamente su contratación para dar cabida a trabajadores residentes locales.

Si el agotamiento del mercado de mano de obra europea provoca que los empresarios vuelvan a mirar a África (pero ahora en femenino), la intensidad de la crisis hace apostar políticamente para que los trabajadores agrícolas locales en desempleo vuelvan al campo, lo que un lustro antes nadie hubiera imaginado. Al principio, esta entrada de residentes locales es más reducida, aunque, conforme se agudiza la crisis y se admiten menos visados por la vía de la contratación en origen, su incorporación se acrecienta. Hay que tener en cuenta que, entre los residentes locales, hay tanto españoles como personas de la recién incorporada Unión Europea.

Aunque no se publican regularmente estadísticas oficiales de la contratación en origen desagregadas por países y sexo, es posible documentar la importancia de los contratos a mujeres marroquíes y cómo van desbancando a los de mujeres del Este a través de estadísticas globales sobre contratos registrados (Gualda, 2009b). Por otra parte, este tipo de informaciones pueden ser solicitadas ad hoc localmente. Basándonos en los datos ofrecidos por la Subdelegación del Gobierno en Huelva, observamos los grandes cambios a que se ha asistido en una década respecto a la procedencia de los contratados. Con ello se puede intuir la complejidad que comporta la logística de este tipo

13. J. LANDERO (2006), «Marruecos colabora con los contratos en origen», Huelva Información, 17 de enero, 3; Odiel Huelva (2008), «La fresa empleará a más de 16.000 marroquíes», Odiel Información, 16 de enero, 21; «La Comisión de Migraciones busca 8.000 extranjeros para la campaña. Estudia la posibilidad de traer mano de obra de Marruecos, Ucrania y Senegal», Odiel Información, 27 de diciembre de 2006, 18; «Asaja buscará temporeros en Ucrania ante las restricciones dentro de la UE», Huelva Información, 2 de diciembre de 2006, 20; «Marruecos paliará el déficit de mano de obra», Huelva Información, 10 de enero de 2008, 17. 
Gráfico 4. Sustitución étnica en la contratación en origen (Huelva)

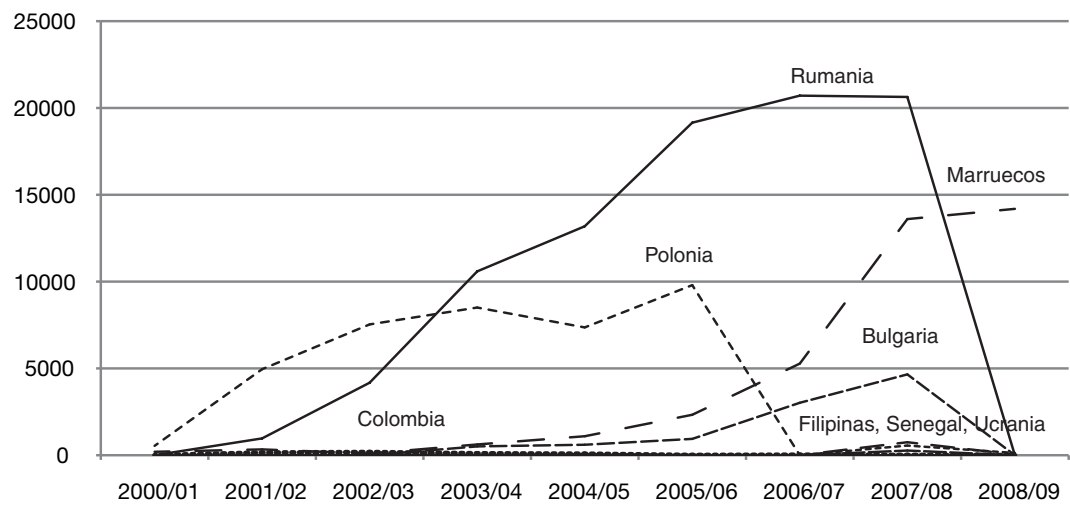

Fuente: elaboración propia a partir de Gordo (2011). Los datos proceden de la Subdelegación del Gobierno de Huelva.

de contrataciones (afectadas directamente por políticas migratorias y por las relaciones internacionales que se producen entre España y terceros países). Los impactos sucesivos que, a escala local, comporta para la población residente en los municipios implicados el hecho de tan rápida sustitución de unos efectivos por otros (a veces con pautas socioculturales muy diferentes) no pasan tampoco desapercibidos, aunque no es el motivo de este artículo. El gráfico 4 resume el intenso proceso de sustitución étnica en la contratación de origen que ha ido teniendo lugar en la provincia de Huelva.

\section{Los efectos de la crisis y el regreso de españoles al campo: discusión}

La crisis desencadena cambios importantes en la tendencia ascendente que llevaba la contratación en origen. El gráfico 5 muestra cómo, si se asocia la tasa de paro de la provincia de Huelva con la pauta seguida en las contrataciones en origen, hay un momento de inflexión en la campaña 20082009, a partir de la cual el incremento del paro se acusa también en el brusco descenso de las contrataciones en origen, acentuado en la campaña 2010-2011. Hay que advertir, no obstante, que la tasa de paro se refiere a la provincia completa, no sólo a los municipios en que se producen las contrataciones en origen. Si correlacionamos la serie de datos de 2001-2009 de estas dos variables, el resultado es de $-0,333$ ( $r$ de Pearson), lo que muestra una conexión que tiene que ver en gran medida con las acciones de política laboral y migratoria que se han desarrollado localmente conforme la crisis se iba agudizando. La tasa de paro es uno de los indicadores que lo reflejan. El gráfico anidado que sigue muestra claramente la inversión de la tendencia en la contratación de origen a partir de que los efectos de la crisis aparezcan localmente de forma más notoria. 
Gráfico 5. Evolución de contratos en origen y tasa anual media de paro en Huelva

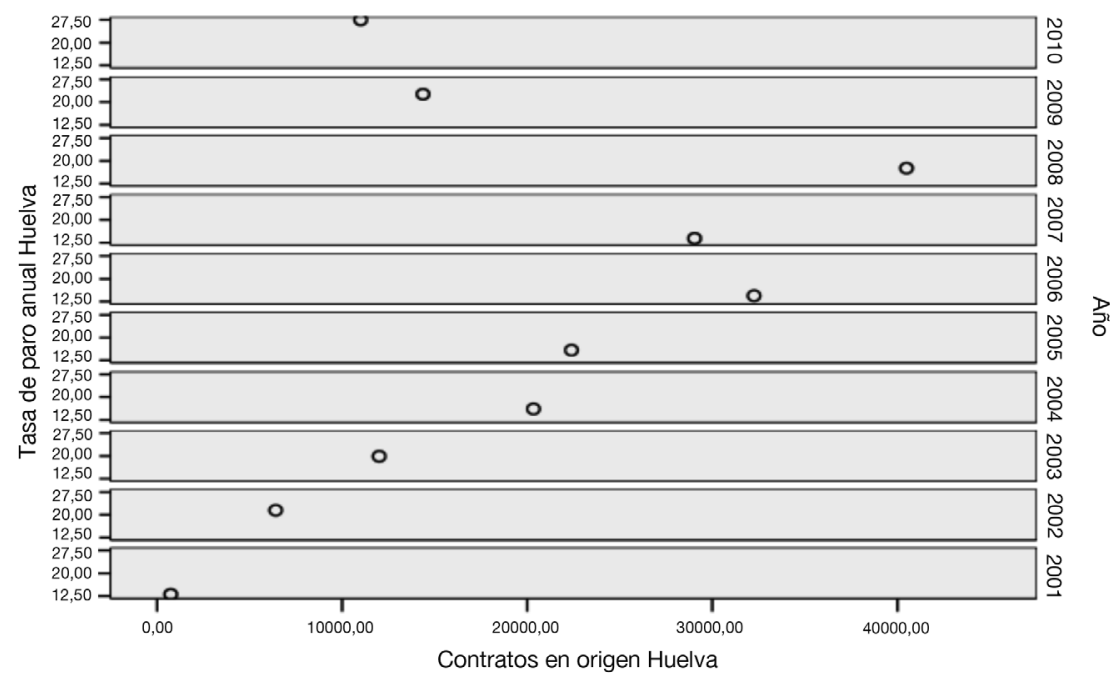

Fuente: elaboración propia.

Antes de llegar a alcanzar las elevadísimas tasas de paro que tuvo como media la provincia en 2010 (27\%), los agentes locales empezaron a jugar con la posibilidad de promocionar la reincorporación de los locales a la agricultura. Así, después de más de una década de la incorporación de la población extranjera al campo, en 2008, uno de los líderes locales propone que los parados nativos trabajen en la fresa ${ }^{14}$. Curiosamente, sería la primera vez en varios años en que se planteaba un giro potencial que podía conducir a que los españoles «sustituyeran» ahora como mano de obra a los extranjeros ${ }^{15}$, fenómeno éste no habitual en los procesos de sustitución laboral étnica. Según explicaba en su momento Juan Antonio Millán, alcalde de Cartaya y portavoz de la Comisión de Migración e Inmigración de la Federación Española de Municipios y Provincias: «la evolución creciente del paro nos ha hecho aumentar los contactos y la cooperación de la Comisión de Ordenación de los Flujos Migratorios con el Servicio Andaluz de Empleo (SAE). Para ello, este año (2008) marcamos una estrategia consistente en que primero era necesario hacer una oferta genérica de empleo agrícola a todos los parados inscritos en el SAE de Huelva» (Millán, 2009: 152).

14. «El portavoz de Migración de la FEMP alienta a los parados españoles a trabajar en la fresa», en http://www.diariometro.es/es/article/efe/2008/08/14/638765/index.xml (14 de agosto de 2008). La noticia fue difundida ampliamente en la televisión, la radio y la prensa locales.

15. Curiosamente, varias semanas después, ante el paro existente, el Ministro de Trabajo e Inmigración anuncia como medida la de reducir la contratación en origen. Véase, por ejemplo, L. ABELLÁN (2008), «Corbacho suprimirá la contratación de inmigrantes en origen en 2009", El País [en línea], 4 de septiembre. <http://www.elpais.com>. 
Como ya habíamos señalado al principio, el desempleo crece en la provincia de Huelva entre 2008 y 2009. En este contexto, «muchas familias hoy quieren volver a trabajar en la fresa» (GD7, mujer de Lepe, 2009). En algunos casos, se anticipaban ya las consecuencias por venir de la crisis traducidas en el retorno al campo: «Yo ya trabajo donde haga falta, en el campo, cuidando mayores, o lo que sea. A mi marido casi ya se le ha acabado el paro y no encuentra nada [...] con tres hijos pequeños que tenemos» (GD8, mujer de Palos de la Frontera, 2009).

Este tipo de situaciones expresa un cambio significativo respecto a lo que venía pasando en campañas previas, cuando el desempleo de la población autóctona no era tan sobresaliente, y diferentes tipos de coberturas - que van agotándose conforme la crisis se prolonga - (subsidios de desempleo, ayuda familiar, trabajo encubierto, trabajo de alguno de los miembros, etc.) ayudaban a subsistir. Otro elemento importante ha sido el modo como los responsables públicos parecen haber manejado la campaña, negociando con empresarios y entidades sindicales, con lo cual han dado juego a la reincorporación de la población autóctona a las tareas agrícolas:

Una de las mejores lecciones que se extraen de la fluctuante campaña 20082009 es la adecuación de los flujos migratorios a las necesidades puntuales del mercado. Hay una crisis económica y los locales, nacionales o extranjeros con su tarjeta de residencia y trabajo, tienen en primer lugar que conseguir empleo, y después está el contrato en origen, señaló el Secretario General de Cooperación e Integración del PSOE. (DE VEGA, A.M. (2009). Odiel Información, 12 de julio: 20. La cursiva es nuestra)

El primer edil valoró el hecho de que durante la campaña se hayan realizado más acciones de las previstas a pesar de que el número de mujeres contratadas en origen se ha reducido y «aunque inicialmente estaba prevista la llegada de 17.000 marroquíes, finalmente sólo han venido 10.400 , fruto de la cooperación de las administraciones con las patronales y sindicatos para el fomento de la contratación local, a la que respondieron los agricultores». (S.P. (2009): «Crece la atención social a los inmigrantes». Huelva Información, 23 de junio: 17)

Se trata ésta de una historia en la que lo que encontramos en esta fase de la crisis es un proceso caracterizado por el retorno de los residentes al campo, inimaginable unos años atrás. Lo cual era previsible en los casos de los países recién incorporados a la Unión Europea, mientras que la vuelta al campo de españoles era insospechada y derivada de la agudización de la crisis. En todo este contexto, la capacidad de regular los flujos migratorios por la vía de la contratación en origen a través de la emisión de visados ha desempeñado localmente un papel clave de control y regulación del flujo migratorio en los momentos de recesión económica.

Es evidente que la contratación en origen es un instrumento que, básicamente, intenta lograr el principal objetivo de los empresarios agrícolas para garantizar la recolección y no quedarse sin mano de obra en los momentos clave. Aunque las contrataciones en origen se han orientado en los últimos años 
en femenino, no es el caso (o no lo debería ser, al menos explícitamente) de las contrataciones a la población autóctona. Por otra parte, la incertidumbre y el recelo que los varones extranjeros parecen haber suscitado ${ }^{16}$, no se produce de forma equivalente en el caso de los autóctonos, ni tampoco respecto a las mujeres extranjeras ${ }^{17}$. De ahí que, aunque en otros escenarios agrícolas clásicos en España la contratación venga siendo mayoritariamente masculina, esta provincia parece haberse ido decantando en femenino ${ }^{18}$, independientemente de tratarse de mujeres del Este o africanas. Se trate de la mayor docilidad (Abdullah, 2005; Moreno, 2009), de sus mejores capacidades y actitudes laborales, de la conveniencia de mantener a personas del mismo sexo en los alojamientos proporcionados por los empresarios en las explotaciones o de otros motivos menos amables sugeridos en el discurso público y que hacen recordar algunos trazos de la famosa novela Two Caravans, o Strawberry Fields - en la versión estadounidense- de Lewycka (2008), las cifras apuntan la tendencia a la feminización del trabajo agrícola cuando se trata de contratos realizados a población extranjera, al menos por la vía de la contratación en origen. También es muy evidente la sensibilidad de la contratación en origen a los devatares económicos (crisis) y su gestión política.

\section{7. «Manteniendo la máquina engrasada». Esbozo de conclusión}

Algunas discusiones recientes sobre el sentido de la migración circular para el desarrollo humano y la sostenibilidad (Newland, 2009; International Organization for Migration, 2010; European Comission, 2011; Ruhs, 2006; De Haas, 2005) sugieren en gran medida que la migración circular, sin poderse comparar con las bondades de la ciudadanía dual, presenta más garantías y seguridad para el inmigrante que los múltiples riesgos asociados a la migración irregular. Entre las ventajas relativas al desarrollo humano, se considera que la migración circular puede favorecer las capacidades de los inmigrantes que tienen la oportunidad de trabajar en otro país. También se argumenta que, desde la perspectiva del inmigrante, este tipo de migración circular no es ni buena ni mala, siempre que se trate de una trayectoria elegida. Al mismo tiempo, puede ser un instrumento que se oriente a ir capacitando y formando al personal que emigra por esta vía, proveyéndolo de oportunidades para el retorno y para la contribución a sus países (Newland, 2009).

En el caso del proyecto Aeneas Cartaya, esto se ha querido articular a través de lo que se ha llamado "gestión ética integral de las migraciones» (Millán,

16. Exacerbado por todo un conjunto de discursos que potencian la asociación de inseguridad ciudadana e inmigración, especialmente en masculino: mafias, drogas, delitos a mano armada, robos, etc.

17. Más allá de las alusiones en el discurso social a la prostitución o la destrucción de parejas.

18. Explicaciones alternativas a las ya señaladas más arriba son también la mayor delicadeza de las mujeres al recoger un producto frágil; su menor estatura media, lo cual es mejor para realizar un trabajo que implica estar continuamente agachándose y que puede generar lesiones de espalda; etc. 
2009), que, además de organizar los flujos migratorios, lleva varios años implementando acciones orientadas a propiciar el desarrollo en los países de origen. Algunas ONG de la zona están trabajando en la misma línea en los últimos años desarrollando acciones formativas que benefician a las personas que acuden a trabajar a la campaña, con vistas a que esos aprendizajes puedan ser rentabilizados en los lugares de origen. El efecto de algunas de estas acciones sobre los lugares de origen tendrá que ser evaluado en el futuro, dado lo incipiente de estas orientaciones hacia el codesarrollo.

Otros elementos que se han valorado positivamente en nuestra área de estudio es que se facilita la documentación, el desplazamiento y la estancia del trabajador a través de la acción de mediadores sociolaborales, monitores, así como todo un dispositivo público de servicios sociales, laborales, educativos, sanitarios u otros a cargo de administraciones, ONG y centrales sindicales. En el caso particular de España, una de las ventajas que se atribuyen para los inmigrantes a la entrada en un proceso de migración circular es que todo el tiempo que pasen entre una y otra campaña puede ser acumulado de cara a poder pedir en el futuro algún permiso de residencia más largo, siempre y cuando se haya cumplido el ciclo de estancia y retorno como establece la ley, lo cual, de acuerdo con las estadísticas que se manejan de personas retornadas a Marruecos, parece se está llevando a cabo en la mayor parte de los casos, mejorando las experiencias de los primeros años, así como los procesos empleados para este tipo de control y conteo de los retornos.

Otro argumento aducido a favor de esta política de migración circular es que no se incrementa de forma permanente el volumen de trabajadores en la provincia ${ }^{19}$, algo que recientemente ha sido destacado por Parrenas (2010) para el caso de artistas filipinos en Japón, lo cual invita a reconceptualizar la migración circular. También se expone que la migración circular es beneficiosa por la generación de remesas para el origen y los incentivos económicos que provocan en el destino migratorio la llegada de varios miles de personas, en tanto que se incorporan nuevos consumidores de bienes y servicios, lo cual propicia beneficios y empleos directos e indirectos. Uno de los aspectos más subrayados es que se minimizan los riesgos de la inmigración, entre otros, las muertes en la travesía del Estrecho. Para los empresarios, que han invertido mucho dinero y han apostado y acabado aceptando esta compleja logística, la migración circular permite experimentar primero a pequeña escala con nuevos países y sus trabajadores, al tiempo que les permite tener mano de obra cuando la necesitan, con lo cual minimizan igualmente sus riesgos. Por otra parte, la introducción y consolidación en algunas empresas agrícolas de acciones destinadas a la gestión intercultural es también un paso importante si se compara con el pasado.

Además, no se pueden despreciar los impactos sociales y económicos que la llegada cíclica de miles de personas producen en un territorio, no sólo sobre

19. Aunque quizás es pronto para evaluar esta circunstancia, teniendo en cuenta el funcionamiento de las redes migratorias en otros países (Massey y Espinosa, 1997). 
la población, sino sobre todo el dispositivo de servicios sociales, médicos, educativos, etc. que se planifica y se monta alrededor de ella, todo lo cual se soporta con fondos públicos. No todo son luces en el desarrollo de estos procesos de migración circular o de contratación en origen, también aparecen algunas sombras, aunque en este artículo apenas las hemos sugerido. Desde críticas a la excesiva feminización hacia la que ha derivado la selección (con costes familiares en el origen), hasta la exclusión de los varones de los trabajos de recogida. La valoración negativa que en algunas ocasiones se emite sobre algunas viviendas y sus condiciones de habitabilidad y de accesibilidad a los núcleos urbanos es otro aspecto a tener en cuenta. Además de las dificultades por parte de la población autóctona para «digerir» tamaños cambios en tan poco tiempo en municipios que se habían mantenido muy tradicionales y nada diversos étnicamente hasta la actualidad. Pero tampoco pueden olvidarse las dificultades que acarrea la selección de mano de obra en otros países, aunque en algunos casos éstas se han ido depurando con la práctica y la experimentación. Para el volumen y la intensidad que supone la campaña, muchos de estos impactos son mínimos, en gran medida por el refuerzo de muchos servicios que tienen lugar en el proceso, así como por el continuo seguimiento local que se articula durante estos meses, facilitado por las instituciones locales y regionales. Pero si la experiencia se mantiene y la contratación en origen se vuelve a potenciar tras la crisis en un contexto europeo de migración circular, es preciso seguir evaluando críticamente su desarrollo y pulir los aspectos más negativos.

Por otra parte, en el caso de Huelva, ninguno de los agentes locales con que hemos contactado, así como algunos expertos en la materia, piensan que los españoles vayan a permanecer trabajando en el campo si la crisis se termina y hay otros empleos disponibles (Gordo, 2011). La vuelta permanente de los españoles al campo es un escenario que no se visualiza, a no ser que se dignificaran bastante las condiciones de trabajo de la agricultura, lo cual, en un contexto de competencia internacional en los mercados, parece inviable, como sugería la tercera vía de Castles (2006). Por este motivo, una de las apuestas locales después de haber experimentado el funcionamiento de la migración circular y habiéndolo evaluado, es la de "mantener la máquina engrasada» para cuando los españoles y los residentes de origen extranjero que hoy trabajan en la agricultura vayan prosperando y cambien de sector. Las peculiaridades de la economía provincial, donde la necesidad de la recogida de la fresa Justo a tiempo coincide algunos meses ya con el inicio de la temporada turística, obligan a ir por delante de la posibilidad de que la mano de obra te abandone y cambie de sector ante una oferta mejor y un trabajo más confortable. Y en este sentido la migración circular ha resultado útil. Por otra parte, romper de golpe en un contexto de crisis con todo el proceso organizativo y logístico que supone una tarea de tal envergadura y que afecta a multiplicidad de agentes sociales, incluidos gobiernos, puede implicar como coste la reducción de la confianza en los mercados proveedores de mano de obra (Marañón, Gualda y Valerdi, 2011). Por eso, algunos actores locales argumentaban que «la máquina 
debe quedar engrasada» incluso en tiempos de crisis, y para eso es preciso que, aunque se reduzca la cifra de contratos, el vínculo organizacional nacional y, sobre todo, internacional no desaparezca. En el fondo, ante la inseguridad de que la fresa quede sin recolectar en el último momento, detrás de la sustitución de mano de obra y de los cambios en la segmentación laboral, se encuentran estrategias meramente instrumentales de abaratamiento de los costes, de evitación de conflictos que repercutan en el trabajo y, especialmente, el intento de los empresarios por ganar "certidumbre», en un contexto en el que la falta de mano de obra en el momento clave supondría la pérdida de la cosecha y de las inversiones de todo el año, lo cual comportaría repercusiones económicas importantes también para la economía de la zona y ello afectaría a muchos municipios de la provincia. La crisis pone de relieve que, más allá de los discursos socioculturales que planean en el ambiente (que cristalizan a veces en perniciosos estereotipos), la prioridad es la recogida, independientemente de quien recoja, siempre que ello no implique un coste excesivamente elevado en personal para el empresario. Pero también pone de relieve que los empresarios no deciden del todo a quién contratar, puesto que en el proceso intervienen políticas y decisiones internacionales, nacionales, regionales y locales. En este sentido, si los españoles están por la labor de volver al campo ${ }^{20}$, puede que se profundice en esta vuelta mientras se mantenga la crisis. Y, de hecho, es lo que ha venido pasando en los últimos tiempos, donde la recolección de la fresa está a cargo de trabajadores nacionales, trabajadores extranjeros asentados ${ }^{21}$ y contratados en origen. Pero realmente nadie prevé que esta situación se prolongue cuando venga la calma.

Por otra parte, incluso aunque globalmente la crisis en España no parece haber supuesto una reducción significativa del volumen de extranjeros que trabajan aqui (Aja, Arango y Oliver, 2011: 14), lo que se espera cuando la crisis termine es precisamente la intensificación de la necesidad de mano de obra de origen foráneo, especialmente en escenarios agrícolas como el descrito, de ahí que las experiencias de cooperación interestatal que se han puesto en marcha montando todo el dispositivo de contratación en origen pueden servir de base para establecer nuevos marcos bilaterales, plurilaterales y multilaterales para la regulación de los flujos, con la meta de beneficiar tanto a los países emisores como receptores, articulación interestatal que es sugerida como una nueva oportunidad global de cooperación internacional que puede derivar de la crisis económica internacional actual (Ghosh, 2011). La experiencia de la migración circular en esta área esperamos pueda permitir reflexionar sobre sus luces y sus sombras en otros escenarios.

20. Lo que no todo el mundo tiene claro: Y. SÁNCHEZ (2009), «La Junta estima que no trabajarán más temporeros nacionales que en 2008», Huelva Información, 17 de marzo, 17; A.B. (2009), «Los parados prefieren el subsidio a trabajar en el sector agrícola», Odiel Información, 17 de marzo, 3 .

21. O que, como europeos, pueden ser contratados en cualquier momento aunque residan gran parte del año en otros países, por ejemplo: Rumanía. 


\section{Referencias bibliográficas}

ABDullah, Noorman (2005). «Foreign Bodies at Work: Good, Docile and Other-ed». Asian Journal of Social Science, 33 (2), 223-245.

Aja, Eliseo; ArangO, Joaquín y Oliver, Josep (eds.) (2011). «La persistencia de la crisis». En: AJA, E.; ARANGO, J. y Oliver, J. (eds.). Inmigración y crisis económica. Impactos actuales y perspectivas de futuro: Anuario de la inmigración en España 2010. Barcelona: Bellaterra Edicions, 12-20.

Beguy, Donatien; Bocquier, Philippe y Zulu, Eliya Msiyaphazi (2010). "Circular migration patterns and determinants in Nairobi slum settlements». Demographic Research, 23, 549-586.

Beltrán, Miguel (2002). "A vueltas con los “terremotos” demográficos en España». Revista Española de Investigaciones Sociológicas, 100, 83-102.

BÖHNING, W.R. (1974). «Inmigration Policies of Western European Countries». International Migration Review, 8 (2), 155-163.

CACHÓn, Lorenzo (2002). "La formación de la "España inmigrante": Mercado y ciudadanía». Revista Española de Investigaciones Sociológicas, 97, 95-126.

- (2009). La "España inmigrante»: Marco discriminatorio, mercado de trabajo y politicas de integración. Barcelona: Anthropos.

CASTLES, Stephen (1985). "The Guests who stayed. The debate on "Foreigners Policy" in the German Federal Republic». International Migration Review, 19 (4), 517-534.

- (1986). "The Guest-Worker in Western Europe. An Obituary». International Migration Review, 20 (4), 761-778.

- (2006). "Guestworkers in Europe: A Resurrection?». International Migration Review, 40, 741-766.

Cerrutti, Marcela y Massey, Douglas (2004). "Trends in Mexican Migration to the United Status, 1965 to 1995». En: Durand, Jorge y MASSEY, Douglas (ed.). Crossing the border: research from the Mexican Migration Project. Nueva York: Rusell Sage, 17-44.

Commission of the European Communities (2004). Commission staff working paper: Annual report on the development of a common policy on illegal immigration, smuggling and trafficking of human beings, external borders, and the return of illegal residents (SEC/2004/1349, de 25 de octubre).

- (2005a). Communication from the Commission to the Council, the European Parliament, the European Economic and Social Committee and the Committee of the Regions: A Common Agenda for Integration Framework for the Integration of ThirdCountry Nationals in the European Union (COM/2005/0389 final, documento del 1 de septiembre).

- (2005b). Communication from the Comission: Policy Plan on Legal Migration (COM/2005/669 final). Bruselas.

- (2007). Communication from the Commission to the European Parliament, the Council, the European Economic and Social Committee and the Committee of the Regions: On circular migration and mobility partnerships between the European Union and third countries (COM/2007/0248 final, documento del 6 de mayo).

Council of THE European Union (2007). Council Decision of 25 June 2007 establishing the European Fund for the Integration of third-country nationals for the period 2007 to 2013 as part of the General programme Solidarity and Management of Migration Flows (2007/435/EC). Official Journal L 168, 28.06.2007, 18-36.

DE HAAS, Hein (2005). "International migration, remittances and development: Myths and facts». Third World Quarterly, 26 (8), 1269-1284. 
EUROPEAN COMISSION (2011). Developing a common European immigration policy [en línea]. <http://ec.europa.eu/home-affairs/doc_centre/immigration/ immigration _intro_en.htm> [Consulta: 12 marzo 2011].

European Parliament and Council of the European Union (2004). «Regulation (EC) No 491/2004 of the European Parliament and of the Council of 10 March 2004 establishing a programme for financial and technical assistance to third countries in the areas of migration and asylum (AENEAS)». Official Journal L 80, 18/03/2004, 1-5.

Food and Agricultural Organization of the United Nations (2010). Mayor Food and Agricultural Commodities and Producers [en línea]. <http://www.fao.org/ es/ess/top/topproduction.html?lang=en\&country=203\&year=200> [Consulta: 19 mayo 2010].

GHOSH, Bimal (2011). The Global Economic Crisis and Migration: Where do we go from here? Ginebra: International Organization for Migration.

Gordo, Mercedes (2009). «Y las polacas habitaron entre nosotros... Preferencia de los agricultores onubenses por las temporeras de Polonia y su situación actual». En: GORDO, Mercedes y FELICIDADES, Jesús (eds.). Explorando los contratos en origen en los campos españoles. Huelva: Universidad de Huelva, 155-184.

- (2011). "Los contratos en origen de temporada a las "marroquinas": Estrategia empresarial para sustituir a las trabajadoras del Este de Europa tras la incorporación de estos países a la UE». En: Congreso Internacional Cooperación Transfronteriza Andalucía, Algarve y Alentejo. Huelva: Universidad de Huelva, 573-593.

GORDON, Ian (1995). "Migration in a segmented labour market». Transactions of the Institute of British Geographers, 20 (2), 139-155.

GUALDA, Estrella (2001). Los procesos de integración social de la primera generación de "Gastarbeiter» españoles en Alemania. Huelva: Universidad de Huelva.

- (2008). «Sobre pluralismo teórico y metodológico, realidades reales-apariencia y terremotos en la estructuración del mercado de trabajo agrícola onubense». En: MeIL, Gerardo y Torres, Cristóbal (comp.). Sociología y Realidad Social, libro a Miguel Beltrán Villalba. Madrid: Centro de Investigaciones Sociológicas, 13131326.

- (2009a). «De polacas a senegalesas: Contratos en origen, sustitución étnica y segmentación del mercado agrícola onubense». Panorámica Social. Inmigrantes en España: participación y convivencia, 8, 71-84.

- (2009b). «Mujeres inmigrantes en la agricultura». En: Moyano, E. (coord.). Agricultura familiar en España 2009. Madrid: UPA. Fundación de Estudios Rurales, 228-233.

GualdA, Estrella y Ruiz, Marta (2004). «Migración femenina de Europa del Este y mercado de trabajo agrícola en la provincia de Huelva, España». Migraciones Internacionales, 2 (4), 36-65.

Hugo, Graeme (1982). "Circular Migration in Indonesia». Population and Development Review, 8 (1), 59-83.

- (2006). "Globalization and changes in Australian international migration». Journal of Population Research, 2 (2), 107-134.

InSTITUTO NACIONAL DE EsTADÍsTICA (2011). «Tasa de paro». Encuesta de población activa [en línea]. <http://www.ine.es/inebmenu/mnu_mercalab.htm> [Consulta: 18 abril 2011].

International Organization for Migration (2010). World Migration Report 2010: The Future of Migration: building capacities for change. Ginebra: IOM. 
Kayser, Bernard (1977). «European Migrations: The new pattern». International Migration Review, 11 (2), 232-240.

KuHN, W.E. (1978). "Guest workers as an automatic stabilizer of cyclical unemployment in Switzerland and Germany». International Migration Review, 12 (2), 210-224.

LEWYCKA, Marina (2008). Two Caravans. Londres: Penguin.

Marañón, Rafael; Gualda, Estrella y Valerdi, Ricardo (2011). «The Dynamics of Circular Migration in Southern Europe: An Example of Social Innovation». ESD Working Paper Series, ESD-WP-2011-01, enero. Massachusetts Institute of Technology. Engineering Systems Division [en línea]. <http://esd.mit.edu/staging/ WPS/2011/esd-wp-2011-01.pdf> [Consulta: 1 febrero 2011].

MÁrqueZ, Juan; Gordo, Mercedes y Delgado, Francisco (2009). "Temporary “contracts in origin" as policy to control immigration in Spain: the "Huelva model" ". Les cahiers de l'URMIS (Unité de Recherche Migrations et Société) [en línea], 12. <http://urmis.revues.org/index878.html> [Consulta: 12 marzo 2010].

MAssey, Douglas (1987). "Understanding Mexican Migration to the United States». The American Journal of Sociology, 92 (6), 1372-1403.

Massey, Douglas S.; Durand, Jorge y Malone, Nolan J. (2002). Beyond Smoke and Mirrors: Mexican Immigration in an Era of Economic Integration. Nueva York: Russell Sage Foundation.

Massey, Douglas y EsPInOSA, Kristine (1997). "What's Driving Mexico-U.S. Migration?: A Theoretical, Empirical, and Policy Analysis». The American Journal of Sociology, 102 (4), 939-999.

MCKAY, Deirdre (2006). "Rethinking indigenous place: Igorot identity and locality in The Philippines». The Australian Journal of Anthropology, 17 (3), 291-306.

MendozA, Cristóbal y HogGarT, Keith (2000). "African Immigrant Workers in Spanish Agriculture». The Center for Comparative Immigration Studies (CCIS), Working Paper [en línea], 2. Universidad de California - San Diego, La Jolla California. <http://www.ccis-ucsd.org/PUBLICATIONS/wrkg2.PDF> [Consulta: 20 mayo 2003].

Millán, Juan (2009). «Modelo Cartaya de migración circular: su definición conceptual y estratégica. "Fórmula de Codesarrollo idónea para fomentar flujos migratorios legales, complementar el control de frontera y la lucha contra el tráfico ilícito de personas y la migración ilegal”». En: GORDO, Mercedes y FELICIDADES, Jesús (eds.). Explorando los contratos en origen en los campos españoles. Huelva: Universidad de Huelva, 145-154.

Ministerio de Agricultura, Pesca y Alimentación (2008). Panorama sociolaboral de las mujeres en el medio rural y en la agricultura: Las mujeres en el medio rural [en línea]. <http://www.mapa.es/es/desarrollo/pags/ mujer/pr_sociolaboral.htm> [Consulta: 14 mayo 2009].

Ministerio de Medio Ambiente y Medio Rural y Marino (2009). Anuario de Estadistica 2008 [en línea]. Madrid. <http://www.mapa.es/ estadistica/pags/anuario/ 2008/Anuario_2008.pdf> [Consulta: 20 mayo 2010].

Ministerio de Trabajo E InMigración (2010a). Anuario Estadistico de Inmigración, 2009. Madrid: Secretaría de Estado de Inmigración y Emigración.

- (2010b). Versión consolidada de la Ley Orgánica 4/2000, de 11 de enero sobre derechos y libertades de los extranjeros en España y su integración social, en su redacción dada por las leyes orgánicas 8/2000, de 22 de diciembre, 11/2003, de 29 de septiembre, 14/2003, de 20 de noviembre, y 2/2009, de 11 de diciembre. Madrid: Subdirección General de Información Administrativa y Publicaciones. 
Moreno, Juana (2009). «Temporeras marroquíes en la agricultura». En: MOYANO, Eduardo (coord.). Agricultura familiar en España 2009. Madrid: UPA. Fundación de Estudios Rurales, 223-227.

Newland, K. (2009). Circular Migration and Human Development: Human Development Research Paper 2009/42 [en línea]. United Nations Development Programme. <http://www.migrationpolicy.org/pubs/newland_HDRP_2009.pdf> [Consulta: 10 marzo 2011].

O'BRIEN, Peter (1988). "Continuity and change in Germany's treatment of nongermans». International Migration Review, 22 (3), 109-134.

ONYEONORU, Ifeanyi Prinuel (2006). «Circular migration and poverty alleviation in developing countries: A comparative study of Nepal, Philippines and Nigeria». Comunicación presentada en la International Sociological Association [en línea]. $<$ http://search.proquest.com/docview/61795872?accountid=14549>.

OSO, Laura y GARSON, Jean Pierre (2005). "The feminisation of international immigration". Migrant Women and the Labour Market: Diversity and Challenges. OECD and European Commission Seminar. Bruselas, 26-27 septiembre.

PARRENAS, R.S. (2010). "Homeward bound: The circular migration of entertainers between Japan and The Philippines». Global Networks, 10 (3), 301-323.

Portes, Alejandro; Guarnizo, Luis y Landolt, Patricia (1999). "The Study of Transnationalism: Pitfalls and Promise of an Emergent Research Field». Ethnic and Racial Studies, 22 (2), 219-237.

RuHS, Martin (2006). "The potencial of temporary migration programmes in future international migration policy». International Labour Review, 145 (1-2), 8-36.

SASSEN, Saskia (1988). The Mobility of Labor and Capital: A Study in International Investment and Labor Flow. Cambridge: Cambridge University Press.

SHIH, Johanna (2002). «...Yeah, I Could Hire This One, but I Know It's Gonna Be a Problem: How Race, Nativity and Gender Affect Employers' Perceptions of the Manageability of Job Seekers». Ethnic and Racial Studies, 25 (1), 99-119.

Solé, Carlota y PARElla, Sonia (2005). «Immigrant Women in Domestic Service: The Care Crisis in the United States and Spain». En: Henke, Holger (ed.). Crossing Over: Comparing Recent Migration in the United States and Europe. Cambridge (MA): Lexington Books, 235-256.

Unión Europea y Ayuntamiento de Cartaya (2008). «Contratación en origen y los contingentes» y "Gestión integral y ética de flujos de migración circular entre Marruecos y Huelva». Proyecto Aeneas Cartaya [en línea]. <http://www.aeneas.es> [Consulta: 23 junio 2008].

WIESE, Johanna y ThORPE, Katherine (2011). Temporary and Circular Migration: Empirical Evidence, Current Policy Practice and Future Options in EU Member Status. Home Office. UK Border Agency. 